\title{
MEDIATION OF INFLAMMATORY ASCITES FORMATION INDUCED BY MACROMOLECULES IN MICE
}

\author{
KÁROLY BAINTNER* \\ Faculty of Agricultural and Environmental Sciences, Institute of Physiology, \\ Biochemistry and Animal Health, University of Kaposvár, Kaposvár, Hungary
}

(Received: 29 July 2017; accepted: 24 November 2017)

\begin{abstract}
The first 60 -min phase of inflammatory ascites formation was studied by intraperitoneally (i.p.) administered macromolecular inducers: yeast cell wall zymosan binds to specific macrophage receptors, polyethyleneimine (PEI) and concanavalin A (ConA), produces non-covalent cross-links on the surface of various cells, while $\lambda$-carrageenan may function as a contact activator. Depletion of peritoneal macrophages was performed by overnight pretreatment with diphtheria toxin in transgenic mice, resulting in a significant $(p<0.01)$ decrease in the induced formation of ascitic fluid. It was shown that induced ascites is mediated partly (PEI, ConA, and carrageenan) or completely (zymosan) by peritoneal macrophages. Inhibition of prostanoid synthesis with indomethacine or of the kallikrein/bradykinin system with aprotinin also produced a significant $(p<0.01)$ but incomplete inhibition. A slight additivity occurred between the different inhibitory effects. In another series of experiments, the i.p. administration of bradykinin (without a macromolecular inducer) also produced marked ascites, which was not affected by macrophage depletion. The origin of the macrophage-independent part of the induced ascites is best explained by the deformation of the mesothelial cell surface, resulting in signal transfer to the underlying endothelium and the passage of ascitic fluid in the opposite direction. The soluble mediators are represented by prostanoids, bradykinin and other, unidentified agonists.
\end{abstract}

Keywords: ascites, mesothelium, macrophage depletion, bradykinin, ConA, zymosan, carrageenan, polycation

*E-mail: rakiab22@gmail.com

This is an open-access article distributed under the terms of the Creative Commons AttributionNonCommercial 4.0 International License, which permits unrestricted use, distribution, and reproduction in any medium for non-commercial purposes, provided the original author and source are credited, a link to the CC License is provided, and changes - if any - are indicated. 


\section{Introduction}

The peritoneal fluid originates mainly from the subperitoneal vessels of the intestines and provides lubrication for the movements of the abdominal organs. The peritoneal macrophages function as sensors and destroyers of microbes and other noxious agents.

In an earlier study [1], a series of macromolecules was tested for ascitesinducing effect [2]. Slowly absorbed macromolecules were used whose effect was mainly restricted to the peritoneal cavity during the period required for the accumulation of protein-rich ascitic fluid. In the present work, four macromolecules were selected for the induction of inflammatory ascites: two complex carbohydrates (zymosan and $\gamma$-carrageenan), a polycation [polyethyleneimine (PEI)], and a plant lectin [concanavalin A (ConA)]. Cellular and molecular mediation of the process was studied in macrophage-depleted and control mice during the first hour of inflammatory ascites, still before the major influx of leukocytes.

\section{Materials and Methods}

\section{Chemicals}

All chemicals were purchased from SIGMA. The stock solution of $1 \mathrm{mg}$ diphtheria toxin (DT) was supplemented with $2 \mathrm{mg}$ bovine serum albumin to decrease attachment to plastic surfaces. PEI (m.w. 750,000) contained 50\% water; the dose was calculated to dry matter. Both inducers and inhibitors were dissolved in physiological saline. ConA was dissolved immediately before each experiment. Indomethacine was first solubilized with Trisma, then a drop of Tween 80 was added, and the $\mathrm{pH}$ adjusted to 7.4 with crystalline $\mathrm{H}_{2} \mathrm{NaPO}_{4}$.

\section{Animals}

Macrophage-depletable, SPF mice of the FVB-Tg(ITGAM-DTR/EGFP)34Lan genetic construction were purchased from Jackson Labs (Bar Harbor, Maine). The macrophages of this strain, primarily the peritoneal ones, had been sensitized to DT by insertion of a section of a simian gene [3]. The mice were bred in our animal house, then kept in cages, fed with commercial chow, and had free access to water.

The experiments complied with the Hungarian Animal Welfare Act XXVIII/ 1998 and Decree 243/1998 (amended in 2012) and were approved by the Veterinary Office of Somogy County 1126/001/SOM/2005, Budapest 175/2011, and by the local ethics committees. 


\section{Experimental protocol}

Female mice were used for the experiments, when they reached $20 \pm 0.5 \mathrm{~g}$ body weight. The macromolecular inducers were injected intraperitoneally (i.p.) in $0.1 \mathrm{ml}$ physiological saline: PEI ( $10 \mathrm{mg} / \mathrm{kg}$ b.w.), zymosan, $\gamma$-carrageenan, and ConA $(25 \mathrm{mg} / \mathrm{kg}$ b.w.). Sixty minutes later, the mice were decapitated under ether anesthesia, the abdomen was opened along the linea alba, and the ascitic fluid was carefully collected with a pipette, always by the same person. The volume was measured by pipetting the fluid into another Eppendorf tube and expressed as \% of body weight.

The inhibitors, namely indomethacine $(8 \mathrm{mg} / \mathrm{b} . \mathrm{w})$ and aprotinin $(100 \mathrm{mg} / \mathrm{b} . w$.$) ,$ were injected subcutaneously (s.c.) in $0.1 \mathrm{ml}$ physiological saline, $20 \mathrm{~min}$ before the induction. Depletion of peritoneal macrophages was performed by s.c. injection of $10 \mathrm{ng} / \mathrm{g}$ b.w. DT in $0.1 \mathrm{ml}$ physiological saline, $18-20 \mathrm{~h}$ before the experiment. Untreated mice of the same strain were used as control. Before the first experiment, the effectiveness of the toxin was checked with Giemsa staining of peritoneal smears.

In another experimental series, bradykinin was used as an i.p. challenge (40 mg/kg b.w.) in 0.1 physiological saline. The mice were killed 40 min later.

\section{Statistics}

Significance of differences was calculated with analysis of variance (least significant difference) of the SPSS program.

\section{Results}

Series A: 60-min experiments with macromolecular inducers

Induction of ascites without any additional treatment was used as positive control (Figures 1-4). Three kinds of negative control groups were used. Little peritoneal fluid could be collected in the control group injected i.p. with physiological saline (Figure 1). Macrophage depletion or the combination of s.c. aprotinin and indomethacine decreased the volume of peritoneal fluid to values close to zero, which represents a small but significant decrease $(p<0.05)$ as compared with the "saline only" group (Figures 1 and 2).

Macrophage depletion with DT markedly and significantly $(p<0.01)$ decreased the accumulation of peritoneal fluid with each of the inducers (Figures 1-4). In the experiment with zymosan, the fluid volumes fell to the level of the i.p. saline control (Figure 1). 


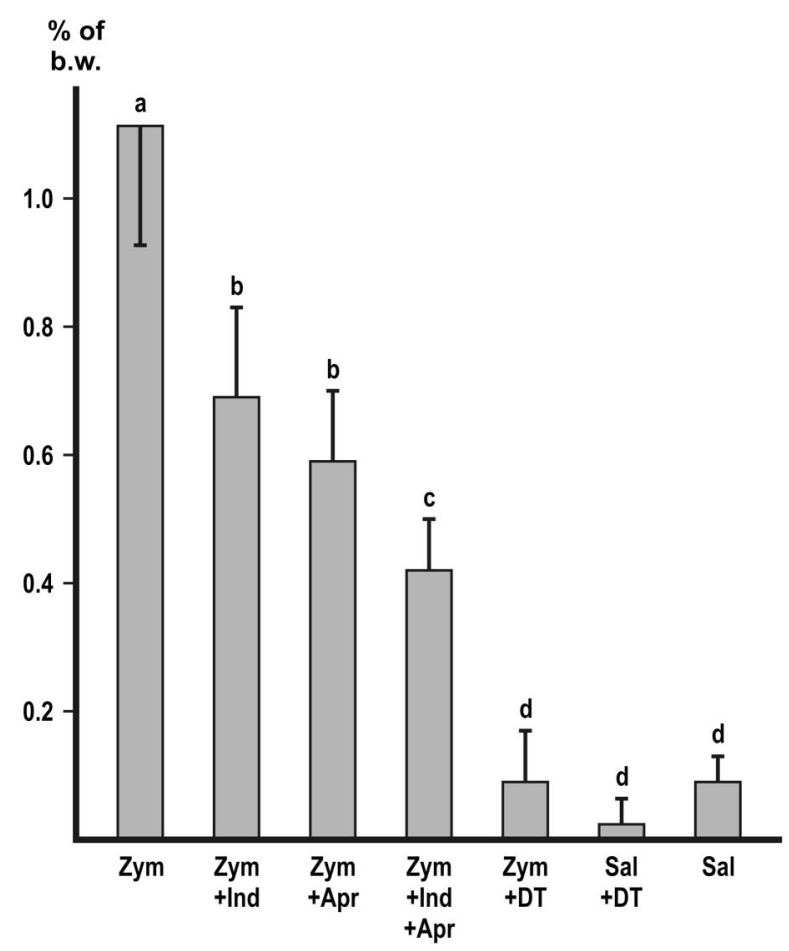

Figure 1. Inhibition of zymosan-induced ascites. Values represent the mean of collected peritoneal fluid expressed in \% of b.w. $\pm \mathrm{SD}, n=6$ or more. Different letters indicate significant difference $(p<0.05)$ between groups. Zym: zymosan; Indo: indomethacine; Apr: aprotinin; DT: macrophage depletion by diphtheria toxin; Sal: physiological saline

Both indomethacine and aprotinin significantly $(p<0.01)$ inhibited the ascites with each of the inducers (Figures 1-4). In the experiments with zymosan and carrageenan, combination of the inhibitors produced a slight, but significant $(p<0.05)$ additive effect (Figures 1 and 2$)$ without achieving complete inhibition.

In the experiment with ConA (Figure 4), depletion of macrophages was combined with the use of inhibitors. Indomethacine and depletion had a slight additive effect $(p<0.05)$, but the combination of depletion with aprotinin did not show additivity.

Series B: 40-min experiments with i.p. bradykinin

Considerable ascites could be provoked by i.p. bradykinin (40 mg/kg b.w.). Macrophage depletion significantly $(p<0.01)$ decreased the fluid volumes 


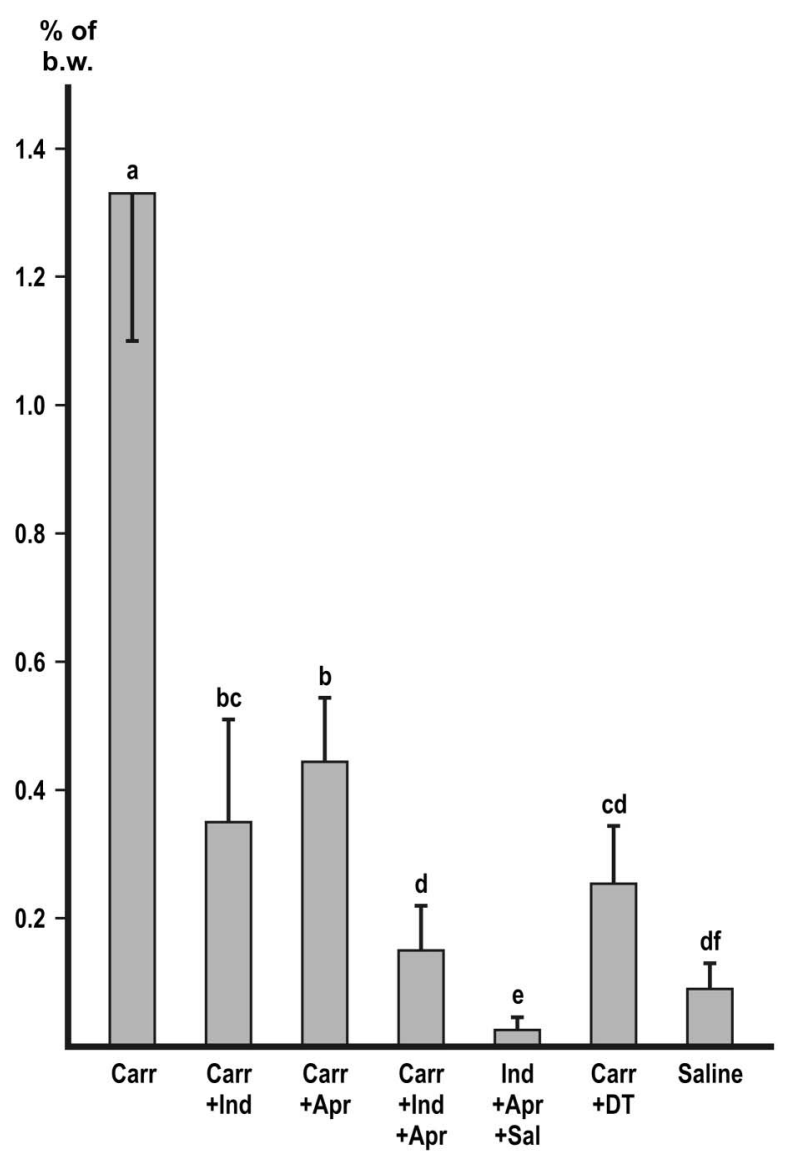

Figure 2. Inhibition of $\gamma$-carrageenan-induced ascites. Values represent the mean of collected peritoneal fluid expressed in $\%$ of b.w. $\pm \mathrm{SD}, n=6$ or more. Different letters indicate significant difference $(p<0.05)$ between groups. Carr: carrageenan; Indo: indomethacine; Apr: aprotinin; DT: macrophage depletion by diphtheria toxin; Sal: physiological saline

(Figure 5A), but subtraction of the respective control values (hatched columns in Figure 5B) eliminated the difference. Combination of indomethacine with bradykinin had no significant effect (Figure 5). In the bradykinin-treated groups (except in the macrophage-deleted one), a small clump of clot was formed regularly in the collected fluid. In the negative control group, the absorption of i.p. saline was not completed at $40 \mathrm{~min}$, and its disappearance was markedly accelerated $(p<0.05)$ in the macrophage-depleted mice (Figure 5). 


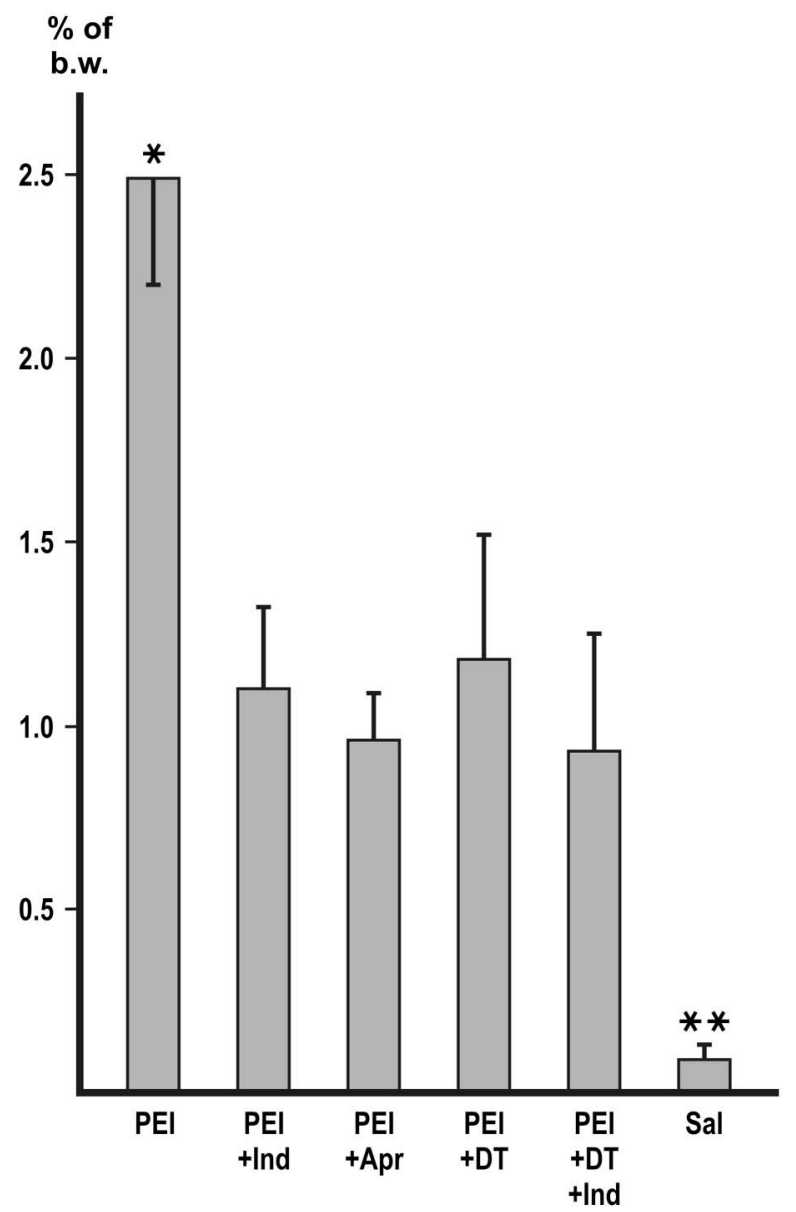

Figure 3. Inhibition of polyethyleneimine-induced ascites. Values represent the mean of collected peritoneal fluid expressed in \% of b.w. $\pm \mathrm{SD}, n=6$ or more. Asterisks indicate significant difference $(p<0.01)$. PEI: polyethyleneimine; Indo: indomethacine; Apr: aprotinin; DT: macrophage depletion by diphtheria toxin; Sal: physiological saline

\section{Discussion}

Series A: 60-min experiments

In addition to the well-known effect of zymosan and carrageenan, a systematic screening of macromolecules for the ability to induce peritoneal exudation was performed in earlier experiments [1]. These macromolecules interact differently with cell membranes and/or receptors and provide means to 


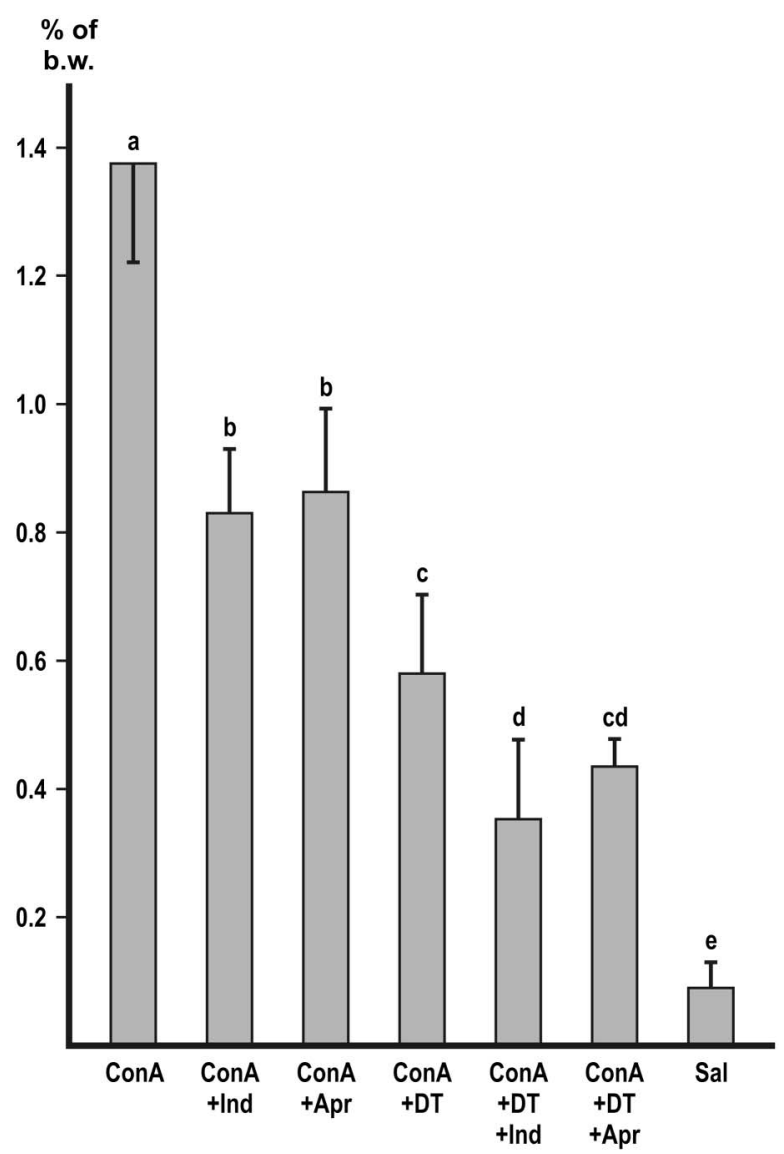

Figure 4. Inhibition of ConA-induced ascites. Values represent the mean of collected peritoneal fluid expressed in \% of b.w. $\pm \mathrm{SD}, n=6$ or more, with the exception of the third group $(n=5)$. Different letters indicate significant difference $(p<0.05)$ between groups. ConA: concanavalin A; Indo: indomethacine; Apr: aprotinin; DT: macrophage depletion by diphtheria toxin; Sal: physiological saline

study the process, focusing on the first hour, before the major influx of leukocytes occurs [2].

In the experimental series $A$, four different macromolecules (zymosan, $\lambda$-carrageenan, PEI, and ConA) were administered i.p. in doses that exerted a submaximal effect. In the macrophage-depleted mice, the inductions were significantly $(p<0.01)$ less effective as compared with the positive control (Figures 1-4). In the experiment with zymosan, the volume of the ascitic fluid decreased to the level of the saline control (Figure 1). It is concluded that 


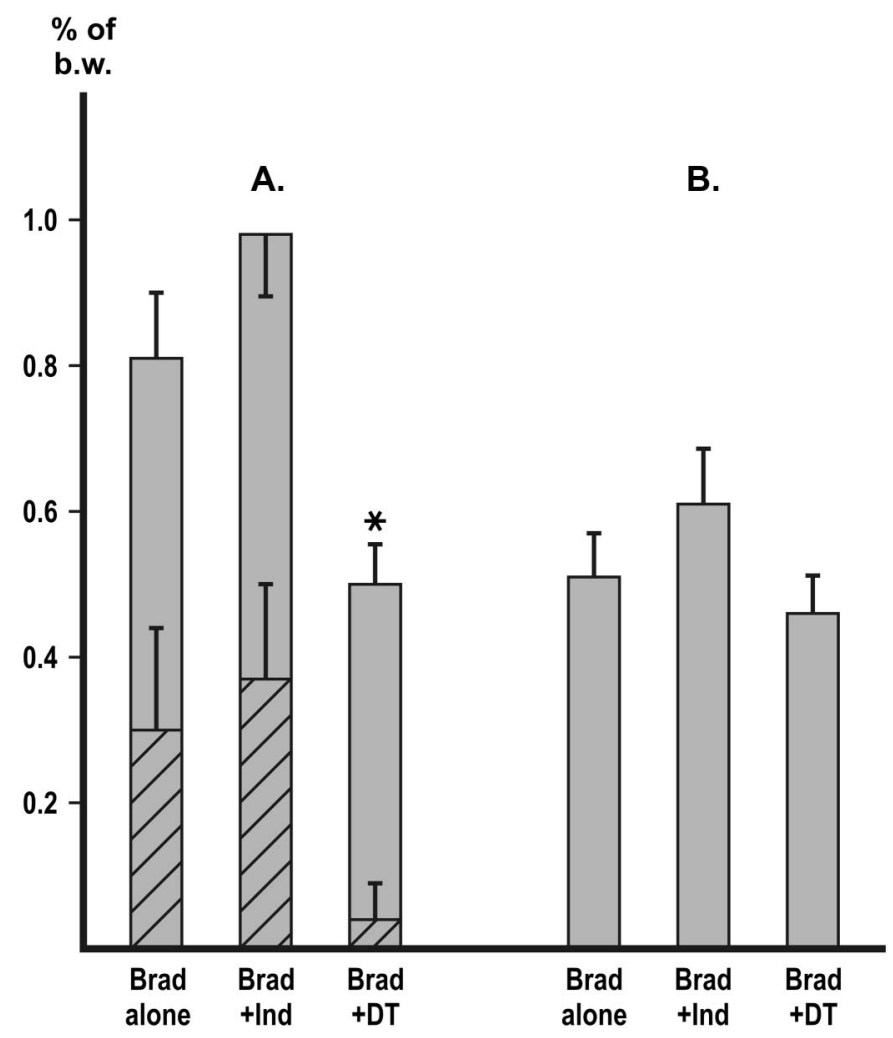

Figure 5. Effect of i.p. bradykinin on the accumulation of peritoneal fluid in 40-min experiments. Values represent the mean of collected peritoneal fluid expressed in $\%$ of b.w. $\pm \mathrm{SD}, n=5$ or more. The asterisk indicates significant difference $(p<0.01)$. A: Bradykinin-induced ascites with or without additional treatments. The respective control groups (saline instead of bradykinin) are hatched. B: The same groups as in A., but with the subtraction of the respective control values. Brad: bradykinin; Indo: indomethacine; DT: macrophage depletion by diphtheria toxin

peritoneal macrophages have an important role in the cellular mediation of induced ascites, especially with zymosan. The regulation of normal peritoneal humidity goes beyond the scope of this study.

In receptor knockout experiments, Yuhki et al. [4] demonstrated that carrageenan-induced pleurisy was mediated by the prostaglandin receptors EP2, EP3, and IP. In the present work, a cyclooxygenase inhibitor (indomethacine) and a kallikrein inhibitor (aprotinin) were used in maximally effective doses. Both inhibitors significantly $(p<0.01)$ decreased the volume of the collected ascitic fluid (Figures 1-4) as compared with the positive control, but complete inhibition could be achieved neither with the inhibitors used singly nor in combination. It is 
concluded that both the prostanoid and the kallikrein/bradykinin systems have an important role in the mediation of induced ascites, but other, unidentified mediators also take part in the process. It is known that bacterial lipopolysaccharides release several cytokines from macrophages [5]. However, Escherichia coli lipopolysaccharide did not produce ascites within the first hour after treatment [6]. The contribution of nitric oxide [7] or mast cell histamine [8] was also excluded.

In some of the experiments, the inhibitory effects were slightly additive, but complete inhibition could not be achieved either by the combination of the inhibitors or by the combination of depletion with one of the inhibitors.

\section{Series B: 40-min experiments}

The accumulation of peritoneal fluid requires a substantial time period after induction. Most of the possible mediator molecules cannot be directly tested due to rapid degradation and/or absorption. However, the molecular size of bradykinin (a nonapeptide) enabled testing when applied in a high dose for a shortened incubation period. In the present experiments, i.p. bradykinin had a marked ascites-inducing effect, which could not be inhibited by indomethacine or by depletion of macrophages. The findings of these experiments are in agreement with the results of the macromolecular inductions and support the notion that the kallikrein-kinin system is one of the mediators of the induced ascites.

In the groups treated with i.p. bradykinin, a small clump of clot consistently appeared in the tubes containing the collected ascitic fluid, which was in agreement with the known procoagulant effect of bradykinin [9]. The passage of the high molecular weight fibrinogen required an enlargement of the pore diameter. From the small clots, the fluid could be sucked out with the pipette and therefore the measured fluid volume was not affected. When macromolecular inducers were used (series $A$ ), the peritoneal fluid was always devoid of clot.

\section{Communication between the mesothelium and the endothelium}

The mesothelial lining and the underlying extracellular material are permeable to water, protein, and other solutes, and the passage is regulated at the endothelium of subperitoneal vessels [10]. Opening of endothelial pores [11] allows the passage of fluid from the plasma to the peritoneal cavity. The signaling molecules take the opposite route, i.e., from the peritoneal macrophages to the endothelium. In earlier experiments, the lectin-aggregated macrophages attached to the mesothelium and produced a marked local effect [2]. The released signaling 
molecules may diffuse across the mesothelium to the capillaries. However, the mesothelium appears to be more than a simple filter, because it is able to release prostanoids $[12,13]$ and bradykinin [14], and it responds to the latter [15].

Zymosan is composed of $\beta 1,3 / 1,6$ glucan and $\alpha / \beta$-mannan and binds to specific receptors on the surface of macrophages [16], which are the cellular mediators of zymosan-induced ascites (Figure 1). Although the other inducers used in the present experiments cannot recognize specialized receptors, their effect is also partly mediated by peritoneal macrophages (Figures 2-4). However, the question arises about the cellular mediation of the macrophage-independent part of the ascites.

The backbone of $\gamma$-carrageenan is composed of alternating galactose and 3,6-anhydrogalactose units. Its rigid, helical structure is highly sulfated and able to bind milk proteins $[17,18]$. It is known that several negatively charged organic or inorganic surfaces activate membrane prekallikrein [19]. Carrageenan may belong to this group of substances. As a comparison, the negatively charged, but non-sulfated poly-DL-glutamate is completely devoid of ascites-inducing ability [1].

The tetravalent ConA binds to $\alpha$-mannosyl residues [20] present on cells in the peritoneal cavity, including macrophages [21] and mesothelial cells [22-25]. The polycationic PEI electrostatically attaches to the negatively charged cell surface, namely to the terminal $\mathrm{N}$-acetylneuraminic acid residues of the glycosyl side chains.

The ability of both ConA and PEI to form non-covalent cross-links is an absolute requirement for the production of peritoneal exudate. The mostly monovalent succinyl-ConA or the small molecular cationic substances lack an inducing effect [1]. The membrane glycoproteins are floating in the liquid crystalline lipid phase and aggregation is prevented by mutual repulsion of the negative charges. Cross-linking of glycoproteins may result in their aggregation, deformation of membrane structure, and activation of membrane-buried [26] prekallikrein and/or membrane-bound phospholipase C. A similar membrane-deforming effect might have occurred in the experiment with carrageenan.

\section{Conclusions}

The origin of the macrophage-independent part of the induced ascites is best explained by the deformation of the mesothelial cell surface, resulting in signal transfer to the underlying endothelium and the passage of ascitic fluid in the opposite direction. The role of mesothelial cells in transperitoneal communication requires further studies. 


\section{Conflict of Interest}

The author has no conflict of interest.

\section{References}

1. Baintner, K.: Inflammatory ascites formation induced by macromolecules in mice and rats. Am J Physiol Regul Integr Comp Physiol 296, R218-R223 (2009).

2. Baintner, K., Bodnár, Z., Kiss, P., L Kiss, A., Lukáts, A.: Effect of intraperitoneally administered plant lectins on leukocyte diapedesis and visceral organ weight in rats and mice. Pathol Oncol Res 13, 139-143 (2007).

3. Palmiter, R.: Diphtheria toxin receptor-mediated conditional and targeted cell ablation in transgenic mice. Nature Biotechnol 19, 731-732 (2001).

4. Yuhki, K., Ueno, A., Naraha, H., Kojima, F., Ushikubi, F., Narumiya, S., Oh-ishi, S.: Prostaglandin receptors EP2, EP3, and IP mediate exudate formation in carrageenininduced mouse pleurisy. J Pharmacol Expt Ther 311, 1218-1224 (2004).

5. Yi, E. S., Ulich, T. R.: Endotoxin, interleukin-1, and tumor necrosis factor cause neutrophildependent microvascular leakage in postcapillary venules. Am J Pathol 140, 659-663 (1992).

6. Baintner, K.: Suppression of ConA-induced ascites by lipopolysaccharide (LPS) in mice. Acta Microbiol Immunol Hung 59, 387-392 (2012).

7. Baintner, K.: Contribution of the kallikrein/kinin system to the mediation of ConA-induced inflammatory ascites. Acta Microbiol Immunol Hung 63, 131-138 (2016).

8. Baintner, K.: Modulation of ConA-induced inflammatory ascites by histamine - Short communication. Acta Microbiol Immunol Hung 62, 87-91 (2015).

9. Kimura, S., Tsuji, H., Nishimura, H., Kato, H., Ukimura, N., Yano, S., Kunieda, Y., Kawano, H., Nakagawa, K., Nakagawa, M.: Bradykinin enhances in vitro procoagulant and antifibrinolytic properties of rat vascular endothelial cells. Thrombosis Res 106, 41-50 (2002).

10. Flessner, M. F.: The transport barrier in intraperitoneal therapy. Am J Physiol Renal Physiol 288, F433-F442 (2005).

11. Venturoli, D., Rippe, B.: Transport asymmetry in peritoneal dialysis: Application of a serial heteroporous peritoneal membrane model. Am J Physiol Renal Physiol 280, F599-F606 (2001).

12. Baer, A. N., Green, F. A.: Cyclooxygenase activity of cultured human mesothelial cells. Prostaglandins 46, 37-49 (1993).

13. Hatanaka, K., Kawamura, M., Ogino, M., Saito, M., Ogino, K., Matsuo, S., Harada, Y.: Expression and function of cyclooxygenase-2 in mesothelial cells during late phase of rat carrageenin-induced pleurisy. Life Sci 65, PL161-PL166 (1999).

14. Varano Della Vergiliana, J. F., Lansley, S., Tan, A. L., Creaney, J., Lee, Y. C., Stewart, G. A.: Mesothelial cells activate the plasma kallikrein-kinin system during pleural inflammation. Biol Chem 392, 633-642 (2011).

15. Andre, M., Rahimi, S., Schollmeyer, P., Pavenstädt, H.: Bradykinin stimulates the intracellular calcium activity in human mesothelial cells. Nephrol Dial Transplant 13, 2047-2052 (1998). 
16. Hollmig, S. T., Ariizumi, K., Cruz, P. D., Jr.: Recognition of non-self-polysaccharides by C-type lectin receptors dectin-1 and dectin-2. Glycobiology 19, 568-575 (2009).

17. Vanni, F.: Carrageenan: A hydrocolloid highly reactive with milk proteins. Mondo del Latte 30, 654-655 (1976).

18. Weinbreck, F., Nieuwenhuijse, H., Robijn, G. W., De Kruif, C. G.: Complexation of whey proteins with carrageenan. J Agric Food Chem 52, 3550-3555 (2004).

19. Kaplan, A. P., Joseph, K., Silverberg, M.: Pathways for bradykinin formation and inflammatory disease. J Allergy Clin Immunol 109, 195-209 (2002).

20. Van Damme, E. J. M., Peumans, W. J., Pusztai, A., Bardocz, S.: Chapter: Canavalia ensiformis. In Handbook of Plant Lectins: Properties and Biomedical Applications. Wiley, New York, 1997, p. 141.

21. Petty, H. R., Ware, B. R.: Macrophage response to concanavalin A: Effect of surface crosslinking on the electrophoretic mobility distribution. Proc Natl Acad Sci U S A 76, 2278-2282 (1979).

22. Hjelle, J. T., Golinska, B. T., Waters, D. C., Steidley, K. R., Miller, M. A., McCarroll, D. R., Dobbie, J. W.: Lectin staining of peritoneal mesothelial cells in vitro. Perit Dial Int 11, 307-316 (1991).

23. Hjelle, J. T., Steidley, K. R., Welch, M. H., Miller, M. A., Dobbie, J. W.: Lectins as probes of membrane carbohydrates in mesothelial cells in vitro. Adv Perit Dial 7, 30-34 (1991).

24. Kortsik, C. S., Freudenberg, N., Riede, U.: Lectin binding sites and immunocytochemical characterization of normal pleural mesothelium. Gen Diagn Pathol 141, 141-146 (1995).

25. Roth, J.: Ultrahistochemical demonstration of saccharide components of complex carbohydrates at the alveolar cell surface and at the mesothelial cell surface of the pleura visceralis of mice by means of concanavalin A. Exp Pathol (Jena) 8, 157-167 (1973).

26. Erez, E., Fass, D., Bibi, E.: How intramembrane proteases bury hydrolytic reactions in the membrane. Nature (Insight) 459, 371-378 (2009). 